\title{
Peltolajiston monimuotoisuutta kesantojen avulla
}

\author{
Terho Hyvönen ${ }^{1)}$, Erja Huusela-Veistola ${ }^{2}$, Mikko Kuussaari ${ }^{3)}$ ja Oskari Härmä4) \\ ${ }^{1)}$ MTT Kasvinsuojelu, 31600 Jokioinen, terho.hyvonen@mtt.fi \\ ${ }^{2)}$ MTT Kasvinsuojelu, 31600 Jokioinen, erja.huusela-veistola@mtt.fi \\ ${ }^{3)}$ Suomen ympäristökeskus, 00251 Helsinki, mikko.kuussaari@ymparisto.fi \\ 4) Jyväskylän yliopisto, Bio- ja ympäristötieteiden laitos, osvealha@cc.jyu.fi
}

\section{Tiivistelmä}

Viljelykiertojen yksipuolistuminen on vähentänyt peltolajiston monimuotoisuutta. Viljelykiertoja voitaisiin monipuolistaa sisällyttämällä niihin viherkesantoja. Nykyisin vallitsevat viherkesannot eivät ole monimuotoisuuden kannalta kaikkein parhaita, sillä ne perustetaan voimakkaasti kilpailevilla monivuotisilla nurmikasveilla. Peltoluonnon monimuotoisuuden kannalta edullisempia olisivat heikommin kilpailevat kasvustot. Tämän tutkimuksen tavoitteena oli selvittää, millaiset kesannot olisivat lajiston monimuotoisuuden kannalta parhaita.

Tutkimuksessa esitellään vuonna 2003 perustetun nelivuotisen kenttäkokeen tuloksia vuodelta 2004. Tutkimuskohteina olivat kasvit (kartoitus) ja pölyttäjähyönteiset (linjalaskennat), tuholaiset ja niiden luontaiset viholliset (kuoppapyydykset ja kelta-ansat) sekä lintujen siemenravinto (maanäytteet) ja hyönteisravinto (haavinnat ja kelta-ansat). Kokeen käsittelyt olivat kesannon ikä (1 tai 2 vuotta), perustamismenetelmä (kylvö suojaviljaan vs. kylvö ilman suojaviljaa) ja siemenseos (voimakkaasti kilpaileva timoteipuna-apila-nurminataseos sekä heikommin kilpaileva nurmirölli-lampaannataseos). Viherkesantoja verrattiin yksinomaan viljaa sisältävään viljelykiertoon sekä sänkikesantoon.

Pölyttäjähyönteisten ja kasvien lajimäärään vaikuttivat siemenseos ja kesannon ikä kesannon perustamistapaa enemmän. Kummassakaan eliöryhmässä ei lajimäärän havaittu poikkeavan siemenseosten välillä ensimmäisen vuoden kesannoilla, mutta toisen vuoden kesannoilla nurmirölli-lampaannatakesantojen lajimäärä oli apila-nurminatakesantoja korkeampi. Sänkikesannoilla saavutettiin jo ensimmäisenä kesänä yhtä suuri kasvien ja pölyttäjien lajimäärä kuin nurmirölli-lampaannataruuduilla kahdessa vuodessa.

Lintujen siemenravinnon tuottoon vaikuttivat kesannon perustamistapa, ikä ja siemenseos. Siemenseokset eivät eronneet ensimmäisenä vuonna, mutta toisen vuoden nurmirölli-lampaannatakesannoilla rikkakasvien siementuotanto oli suurempi. Yksivuotisten kesantojen runsain laji oli pihatähtimö. Toisen vuoden kesannoilla runsaimpia lajeja olivat peltosaunio ja peltolemmikki. Lintujen hyönteisravinnossa tärkeimpiä ryhmiä olivat kärpäset ja sääsket. Kärpäsiä oli runsaasti toisen vuoden nurmirölli-lampaannataja sänkikesannossa sekä ohrakasvustoissa. Sen sijaan sääskien määrissä ei havaittu eroja kasvustojen välillä. Luteita ja kaskaita oli eniten suojaviljaan kylvetyssä puna-apila-nurminatakesannossa, kun taas loispistiäiset viihtyivät nurmirölli-lampaannata- ja sänkikesannoissa. Kasvuston ikä oli tärkein tuholaisten ja niiden luontaisten vihollisten määrään vaikuttava tekijä: tuholaisten (kahukärpänen ja aaltojuovakirppa) määrä väheni ja luontaisten vihollisten (hämähäkit) määrä kasvoi kesannon iän myötä.

Lyhytaikaisten viherkesantojen avulla voidaan lisätä eri eliöryhmien lajiston monimuotoisuutta. Kesantojen paremmuus siemenseoksen, iän ja perustamistavan suhteen riippuu eliöryhmästä.

\section{Asiasanat}

peltolinnut, rikkakasvit, pölyttäjähyönteiset, tuhohyönteiset 


\section{Johdanto}

Karjatalouden ja kasvintuotannon eriytyminen on johtanut viljelykiertojen yksipuolistumiseen viljan tuotantoalueella Etelä- ja Länsi-Suomessa. Monivuotisten nurmikasvien katoaminen viljelykierrosta vaikuttaa lajiston monimuotoisuuteen. Yksi ratkaisu monimuotoisuuden säilyttämiseen ovat viherkesannot, jotka monipuolistavat ja runsastavat niin kasvistoa kuin muutakin eliöstöä (Corbet 1995, Evans 1997, SteffanDewenter \& Tschartnke 1997).

Kesannointi on yksi maatalouden ympäristötuen toimenpiteistä. Ensimmäisellä maatalouden ympäristötuen tukikaudella (1995-1997) tuettiin pitkäaikaisten viherkesantojen perustamista. Toisella tukikaudella tämä ei ole ollut mahdollista, mutta yksi- tai kaksivuotisia kesantoja perustettiin CAP-tuella. Noin kolmannes Suomen tiloista velvoitettiin kesannoimaan vähintään 10 \% peltoalastaan CAP-säännösten perusteella. Vuonna 2004 viherkesantojen pinta-ala Suomessa oli 0.2 miljoonaa hehtaaria (Maa- ja metsätalousministeriö 2004). Valmisteilla olevan maatalouden ympäristötuen (2007-2013) yhdeksi perustoimenpiteeksi on ehdotettu monivuotista viherkesantoa, jonka pituus maksimissaan olisi kolme vuotta.

Lajiston monimuotoisuuden kannalta nykyisin vallitsevat viherkesannot eivät ole kaikkein parhaita. Ne perustetaan tehokkaasti kilpailevilla monivuotisilla nurmikasveilla, jolloin kasvustoista tulee tiheitä monokulttuureita. Lajiston monimuotoisuuden kannalta edullisempia olisivat heikommin kilpailevat kasvustot, jolloin siemenpankista taimettuu enemmän rikkakasvilajeja (Fisher \& Davies 1991, Cloutche ym. 1995). Myös kesannon ikä ja perustamistapa vaikuttavat kesantojen kasvillisuuteen ja sitä kautta eläimistöön (Corbet 1995). Tässä tutkimuksessa tutkittiin siemenseoksen, iän ja perustamistavan vaikutusta kesantojen lajiston monimuotoisuuteen. Tutkimus kuuluu Monimuotoisuuden tutkimusohjelmaan (Mosse 2003-2006).

\section{Aineisto ja menetelmät Koejärjestely}

Lyhytaikaisten viherkesantojen kasvi- ja hyönteislajiston monimuotoisuutta tutkittiin Jokioisiin vuonna 2003 perustetussa neljävuotisessa kenttäkokeessa (tässä esitellään vuoden 2004 tuloksia). Koeasetelma oli satunnaistettujen täydellisten lohkojen koe, jossa käsittelyillä oli neljä toistoa. Koeruudun koko oli 0,3 hehtaaria (44 m x 66 m). Koekesannot erosivat toisistaan siemenseoksen, iän (1. tai 2. vuoden kesanto) ja perustamistavan (kylvetty suojaviljaan / ei suojaviljaa) suhteen. Siemenseoksina käytettiin voimakkaasti kilpailevaa nurminata-puna-apilaseosta sekä heikommin kilpailevaa nurmirölli-lampaannataseosta. Molemmissa siemenseoksissa oli myös timoteita. Viherkesantojen lajistoa verrattiin sänkikesantoon ja ohraan (Taulukko 1).

Taulukko 1. Kesantokokeen käsittelyt.

\begin{tabular}{lcc} 
Kesantotyyppi & Siemenseos/viljelykasvi & Kylvövuosi \\
\hline Vilja (ohra) & Ohra & 2004 \\
1-vuotinen sänkikesanto & Ohra & 2003 \\
1-vuotinen seos 1 & Nurmirölli-Lampaannata & 2004 \\
1-vuotinen seos 2 & Puna-apila-Nurminata & 2004 \\
Suojaviljaan kylvetty 2-vuotinen seos 1 & Nurmirölli-Lampaannata & 2003 \\
Suojaviljaan kylvetty 2-vuotinen seos 2 & Puna-apila-Nurminata & 2003 \\
2-vuotinen seos 1 & Nurmirölli-Lampaannata & 2003 \\
2-vuotinen seos 2 & Puna-apila-Nurminata & 2003
\end{tabular}

\section{Näytteenotto}

Kasvien runsautta kartoitettiin kaksi kertaa kasvukauden aikana (kesä- ja heinäkuussa) arvioimalla kaikkien lajien sekä kukkivien kasvien runsaus yhdeksänportaisella asteikolla. Pölyttäjähyönteiset laskettiin linjalaskennoin neljä kertaa kasvukauden aikana (kesä- ja heinäkuussa). Rikkakasvien siemennäytteet otettiin syyskuun lopussa. Kultakin koeruudulta otettiin $2010 \times 10$ cm:n maanäytettä pintamaasta, josta siemenet eroteltiin.

Maanpinnalla liikkuvia petoniveljalkaisia (hämähäkit, maakiitäjäiset ja lyhytsiipiset) kerättiin kuoppapyydyksillä ja kasvustossa eläviä hyönteisiä keltaisilla liimapyydyksillä. Viikon pituisia keruujaksoja 
oli kolme (kesä-, heinä- ja elokuussa), mutta runsaiden sateiden ja pellon märkyyden vuoksi kaksi jälkimmäistä keruujaksoa jouduttiin hylkäämään kuoppapyydysaineistosta. Lisäksi kokeesta otettiin haavintanäytteet (60 haavinvetoa/näyte) kaksi kertaa heinäkuussa. Samana vuonna kylvetyistä kesannoista ei haavintanäytettä voitu ottaa kasvuston mataluuden vuoksi.

Eri eliöryhmien laji- ja yksilömäärien eroja kesantotyyppien välillä vertailtiin varianssianalyysillä. Tarvittaessa käytettiin logaritmimuunnosta tai ei-parametristä varianssianalyysiä.

\section{Tulokset ja tulosten tarkastelu}

\section{Kasvit ja pölyttäjähyönteiset}

Siemenseos sekä kesannon ikä vaikuttivat kasvien ja pölyttäjähyönteisten lajimäärään enemmän kuin kesannon perustamistapa (Kuva 1). Kummassakaan eliöryhmissä ei lajimäärän havaittu poikkeavan siemenseosten välillä ensimmäisen vuoden kesannoilla $(\mathrm{P}>0,05)$, mutta toisen vuoden kesannoilla nurmiröllilampaannataruutujen lajimäärä oli apila-nurminataruutuja korkeampi $(\mathrm{P}<0,001)$. Kesannon ikä vaikutti positiivisesti pölyttäjien lajimäärään nurmirölli-lampaannatakesannoilla. Sen sijaan kukkivien kasvien lajimäärä oli alhaisempi toisen vuoden apila-nurminataseoksen koeruuduilla. Perustamistavan (kylvö suojaviljaan) vaikutus lajimääriin ei ollut selkeä. Sänkikesannoilla saavutettiin jo ensimmäisenä kesänä yhtä suuri kasvien ja pölyttäjien lajimäärä kuin nurmirölli-lampaannataruuduilla kahdessa vuodessa.

Odotusten mukaisesti heikommin kilpaileva nurmirölli-lampaananataseos oli lajirikkaampi kuin vahvemmin kilpaileva apila-nurminataseos. Runsaimmat kasvilajit olivat yksivuotisilla kesannoilla tyypillisiä yksivuotisia rikkakasveja, kuten peltomatara, pihatähtimö ja saunakukka. Apila-nurminatakasvustojen kehittyessä heikoimmat yksivuotiset joutuivat väistymään, jolloin lajimäärä laski. Tämä tuli toisena vuonna esiin, kun kasvusto oli voimakkaasti kehittynyt. Vahvaa apila-nurminatakasvustoa vastaan pystyivät kilpailemaan ainoastaan voimakkaasti kilpailevat monivuotiset lajit, kuten juolavehnä, pelto-ohdake ja pujo.

Pölyttäjähyönteisiä oli eniten samoilla koekäsittelyillä, joilla kasvien lajimäärä oli suurin (Kuva 1). Kukkivien kasvien runsaus oli kuitenkin kasvien lajimäärää parempi pölyttäjien runsauden selittäjä. Kesantojen runsaslukuisimpia pölyttäjiä olivat mantu- ja hevoskimalainen sekä perhosista niittoyökkönen ja tesmaperhonen.

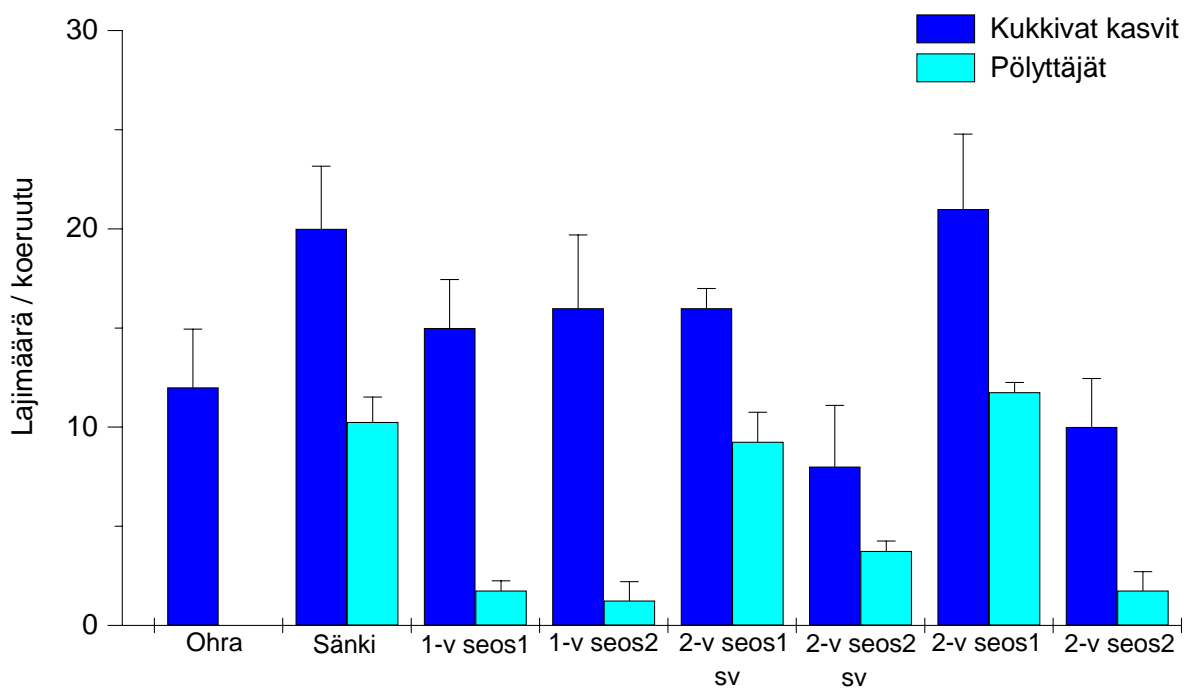

Kuva 1. Kasvien ja pölyttäjähyönteisten lajimäärät (keskiarvo ja keskihajonta) kesantokokeessa.

\section{Lintujen siemenravinto}

Kesannon perustamistavalla, iällä ja siemenseoksella oli merkitystä rikkakasvien siementuotannolle (Kuva 2). Siemenseokset eivät eronneet ensimmäisenä vuonna rikkakasvien siementuoton suhteen $(\mathrm{P}>0,05)$. Toi- 
sen vuoden suojaviljaan kylvetyn apila-nurminatakesannon rikkakasvien siemenmäärät olivat alhaiset, jolloin rikkakasvien siementuotanto oli nurmirölli-lampaannataseoksilla suurempi $(\mathrm{P}<0,001)$. Ilman suojaviljaa kylvetyn apila-nurminataseoksen siementuoton keskiarvot olivat nurmirölli-lampaannataseosta korkeammat, mutta suuresta vaihtelusta johtuen erot eivät olleet tilastollisesti merkitseviä. Yksivuotisten kesantojen runsain laji oli pihatähtimö. Toisen vuoden kesannoilla runsaimpia lajeja olivat peltosaunio, peltolemmikki, jauhosavikka ja peltomatara.

Kesantojen avulla voidaan lisätä lintujen siemenravintoa. Edullisimpia siementuoton suhteen näyttäisivät olevan toisen vuoden kesannot. Suojavilja näyttää pystyvän vähentämään joidenkin lajien, kuten jauhosavikan, siementuottoa ensimmäisenä vuonna.

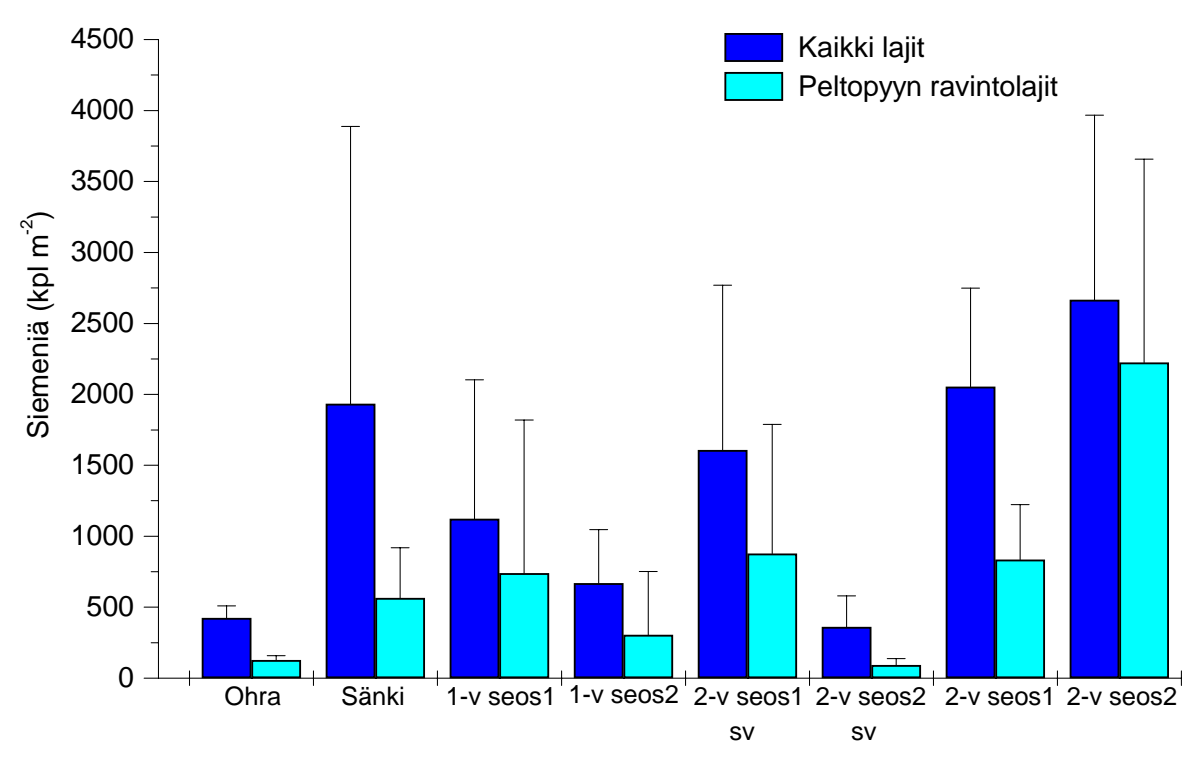

Kuva 2. Kaikkien kasvilajien ja peltopyyn ravinnossa tärkeiden kasvilajien (Pulliainen 1984) siementen runsaus (keskiarvo ja keskihajonta) kesantokokeessa.

\section{Lintujen hyönteisravinto}

Heinäkuussa otetuissa haavintanäytteissä eri hyönteisryhmien runsaudet vaihtelivat paljon erilaisten kasvustojen välillä (Kuva 3a). Kärpäsiä oli ohrakasvustossa selvästi runsaammin kuin kesannoissa $(\mathrm{P}<0,05)$, mutta sääskimäärissä ei merkitsevää eroa eri kasvustojen välillä havaittu. Suojaviljaan kylvetyssä punaapila-nurminatakesannossa oli selvästi eniten luteita ja kaskaita $(\mathrm{P}<0,01)$. Nurmirölli-lampaannata- ja sänkikesannoissa oli muita kasvustoja enemmän loispistiäisiä $(\mathrm{P}<0,01)$, jotka pölyttäjien tapaan käyttävät mettä ja siitepölyä ravintonaan.

Kesän 2004 kelta-ansanäytteitä dominoivat kärpäset ja sääsket, joita oli yli $95 \%$ kokonaissaaliista (Kuva 3b). Sääskien määrissä ei ollut eroa eri käsittelyiden välillä, mutta kärpäsmäärissä erilaisten kesantojen välillä oli merkitsevä ero $(\mathrm{P}<0,05)$. Eniten kärpäsiä oli toisen vuoden nurmirölli-lampaannata- ja sänkikesannossa.

\section{Tuholaiset ja niiden luontaiset viholliset}

Kasvustossa ja maan pinnalla elävien hyönteisten elinympäristönä ensimmäisen vuoden viherkesannot ja kevätviljakasvustot eivät juuri poikenneet toisistaan. Viljojen tuholaislajeja - kahukärpäsiä ja aaltojuovakirppoja - oli samana vuonna perustetuissa viherkesannoissa jokseenkin yhtä paljon kuin ohrassa (Kuva 4). Sen sijaan toisen vuoden kesannoissa tuholaismäärät olivat pienemmät $(\mathrm{P}<0,05)$. 


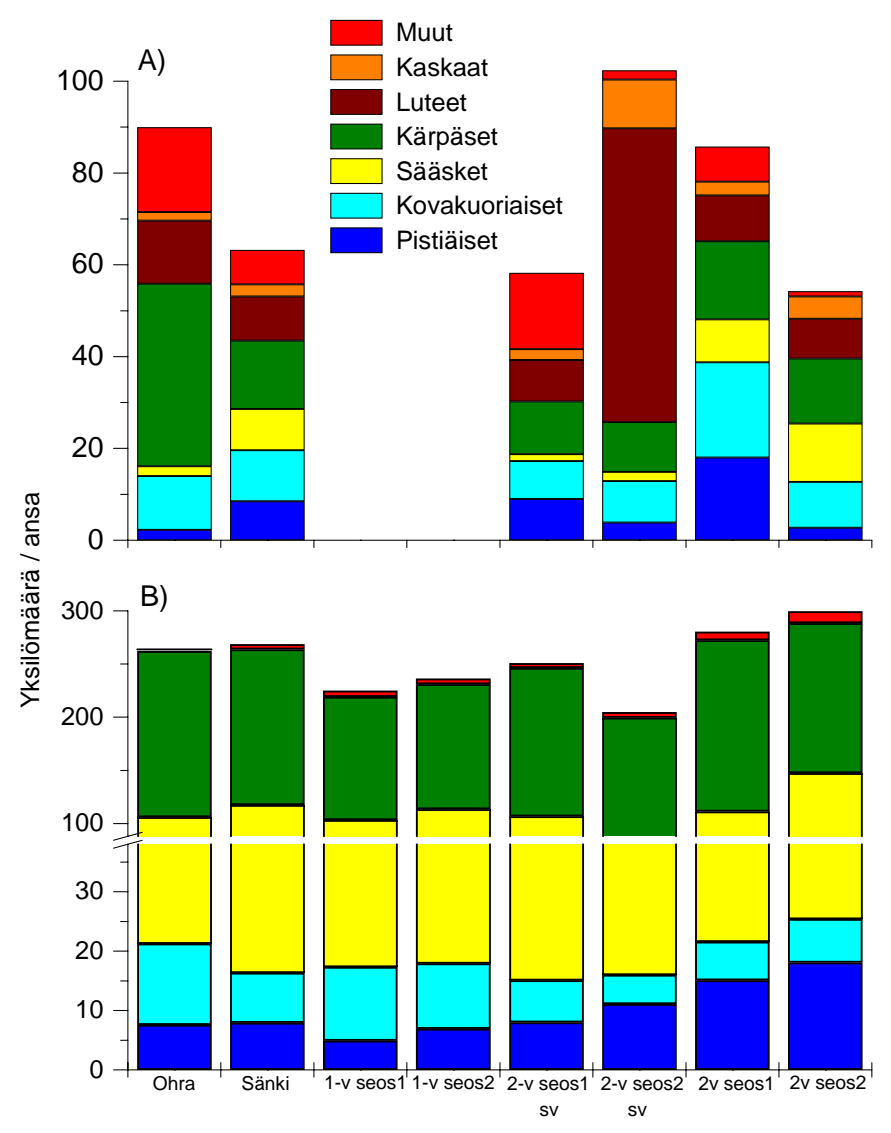

Kuva 3. Eri hyönteisryhmien runsaudet kesantokokeesta otetuissa A) haavinta- ja B) kelta-ansanäytteissä. Lukumäärät ovat kahden (A) ja kolmen (B) näytteenottokerran keskiarvoja. Kelta-ansanäytteissä luokka muut sisältää myös luteet ja kaskaat.

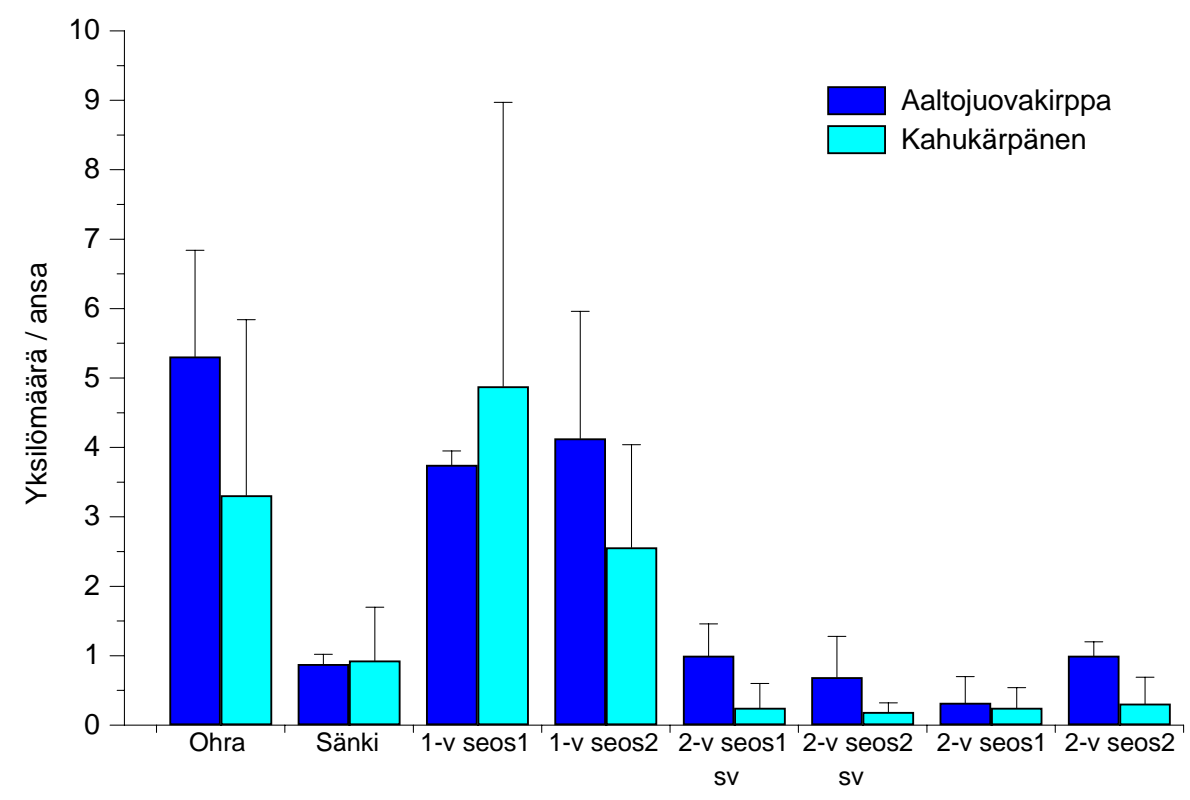

Kuva 4. Aaltojuovakirpan ja kahukärpäsen runsaudet kesantokokeesta otetuissa kelta-ansanäytteissä. Lukumäärät ovat kolmen näytteenottokerran keskiarvoja (keskihajonta suluissa). 
Tuholaisten luontaisista vihollisista runsain ryhmä oli hämähäkit, joita alkukesästä oli eniten toisen vuoden kesannoissa ja sänkikesannossa $(\mathrm{P}<0,001)$. Toisen maan pinnalla liikkuvan petoniveljalkaisryhmän, maakiitäjäisten, määrissä ei havaittu eroa erilaisten kesantojen ja ohran välillä, vaikka monet lajeista talvehtivat pysyvissä kasvustoissa (Kuva 5).

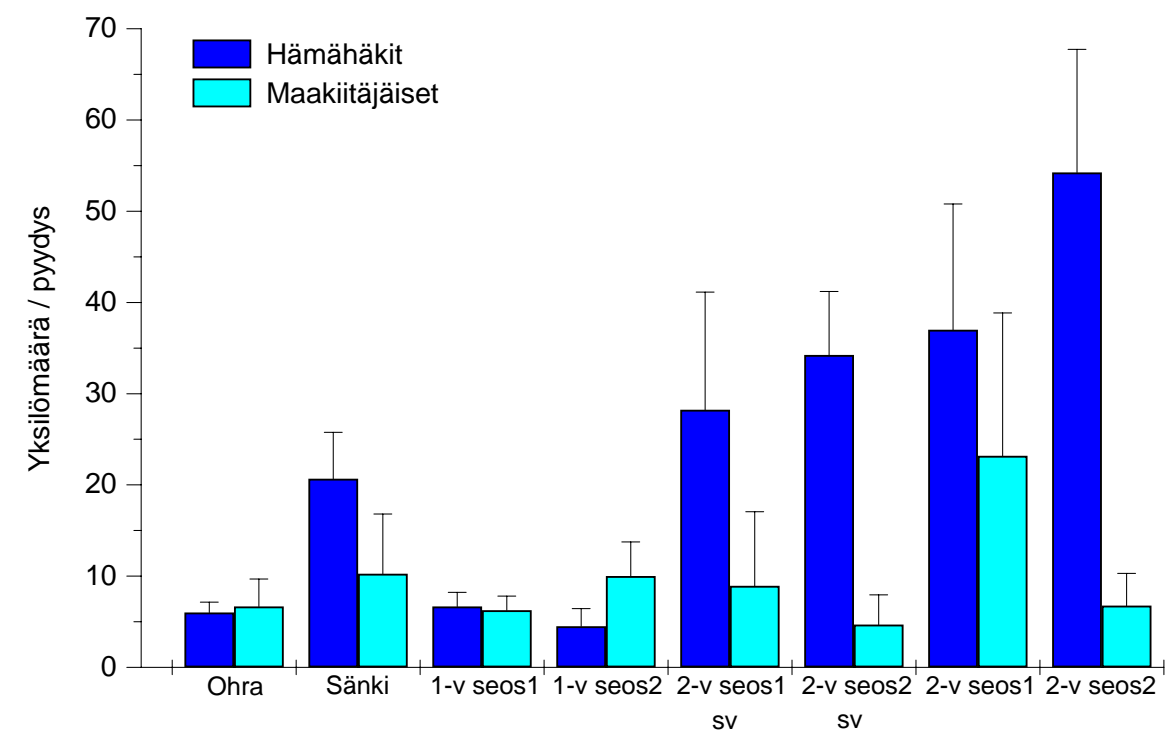

Kuva 5. Hämähäkkien ja maakiitäjäisten runsaudet kesantokokeesta otetuissa kuoppapyydysnäytteissä kesäkuussa (keskiarvo ja keskihajonta).

\section{Johtopäätökset}

Kenttäkokeen tulokset osoittivat, että kesantojen paremmuus siemenseoksen, iän ja perustamistavan suhteen riippuu eliöryhmästä. Heikommin kilpaileva nurmirölli-lampaannata-siemenseos osoittautui apilanurminataseosta edullisemmaksi kasvien ja pölyttäjähyönteisten lajimäärille sekä lintujen siemenravinnolle. Siemenseoksen vaikutus tuli kuitenkin näkyviin vasta toisena kesantovuonna.

Kasvuston ikä oli erityisen tärkeä maassa ja kasvillisuudessa liikkuville hyönteisille, etenkin tuholaisille ja niiden luontaisille vihollisille. Ensimmäisen vuoden kesannot eivät elinympäristönä juurikaan poikkea viljakasvustosta hyönteisten elinympäristönä. Kasvustojen pysyvyys onkin monen hyönteisryhmän säilymisen kannalta siemenseosta tärkeämpää, sillä monivuotinen kasvusto tarjoaa ravinnon lisäksi suoja- ja talvehtimispaikkoja.

Kesannon perustamistavan vaikutus tuli selkeimmin esiin rikkakasvien siementuotannossa. Suojavilja kilpailee hitaasti kasvuun lähteviä heiniä tehokkaammin yksivuotisia rikkakasveja vastaan pystyen hillitsemään joidenkin rikkakasvilajien siementuottoa.

Lyhytaikaisten viherkesantojen avulla voidaan lisätä eri eliöryhmien lajiston monimuotoisuutta. Niinpä kesantojen sisällyttäminen valmisteilla olevaan maatalouden ympäristötukeen on perusteltua. Jotta kesannot rikastuttaisivat yksipuolisesti viljan viljelyyn keskittyviä viljelykiertoja, niiden sijoittamiseen pitäisi kiinnittää huomiota. Kesannot tulisi sijoittaa peltoaukeille, joilla ne eniten rikastuttavat yksipuolisia viljelykiertoja. Tämä olisi erityisen tärkeää lintujen ja tuholaisten luontaisten vihollisten kannalta, joille kesannoilla on merkitystä paitsi ruokailupaikkana myös elinympäristönä.

\section{Kirjallisuus}

Cloutche, P., Peeters, A. \& van Bol, V. 1995. Management of different covers of set-aside for weed control. Brighton Crop Protection Conference - Weeds 1995: 339-346.

Corbet, S. 1995. Insects, plants and succession: advantages of long-term set-aside. Agriculture, Ecosystems and Environment 53: 201-217

Evans, A.D. 1997. Seed-eaters, stubble fields and set-aside. Brighton Crop Protection Conference - Weeds 1997: 907-914 
Fischer, N.M. \& Davies, D.H.K. 1991. Effectiveness of sown covers for the management of weeds in set-aside fallows: the Bush trials. Brighton Crop Protection Conference - Weeds 1991: 387-394.

Maa- ja metsätalousministeriö. 2004. Maatilatilastollinen vuosikirja 2004. TIKE. 268 s.

Pulliainen, E. 1984. Changes in the composition of the autumn food of Perdix perdix in west Finland over 20 years. Journal of Appl. Ecol. 21: 133-139.

Steffan-Dewenter, I. \& Tschartnke, T. 1997. Early succession of butterfly and plant communities on set-aside fields. Oecologia 109: 294-302. 